\title{
Revenue management education (RevME), 30 April-2 May 2015, University of Delaware, USA
}

Received (in revised form): 2nd July 2015

\author{
Larissa Koupriouchina ${ }^{a}$, Jean-Pierre van der Rest ${ }^{\mathbf{b}}$ and Xuan Lorna Wang ${ }^{\mathbf{c}}$ \\ ${ }^{a}$ Hotelschool The Hague, The Hague, The Netherlands; ${ }^{b}$ Department of Business Studies, Leiden University, \\ Leiden, The Netherlands; and ${ }^{C}$ London School of Hospitality and Tourism, University of West London, London, \\ UK
}

Larissa Koupriouchina is a Senior Lecturer in Revenue Management and Research fellow at Hotelschool The Hague. Next to teaching, she is working on her PhD degree at Leiden University, The Netherlands. Her doctoral work is sponsored by the research grant of the Netherlands Organization for Scientific Research (NWO) and focuses on human-computer interactions between revenue managers and revenue management systems. Before starting her career in education, she worked for over 10 years on revenue and profit recovery projects.

Jean-Pierre van der Rest is an Associate Professor of Business Administration at Leiden University, Department of Business Studies. He previously held positions as Chaired Professor, Director of Research and Associate Dean at Hotelschool The Hague. He is an Associate Editor for Cornell Hospitality Quarterly and the International Journal of Revenue Management. Recipient of research grants and awards, his work is published in leading scholarly books and international journals. His research interest includes revenue management, pricing and small business failure.

Xuan Lorna Wang is an Associate Professor at London School of Hospitality and Tourism, University of West London? Her PhD research investigated revenue management impacts on customer relationship development; she has a string of publications in leading marketing and hospitality management journals. She serves on the editorial boards of Journal of Revenue and Pricing Management and International Journal of Hospitality and Event Management. Before her academic career, she held a number of management positions in hotel Operations Management and Sales and Marketing in China and in the United Kingdom.

Correspondence: Larissa Koupriouchina, Hotelschool The Hague, Brusselselaan 2, The Hague $2587 \mathrm{AH}$, The Netherlands

E-mail: I.koupriouchina@hotelschool.nl

\begin{abstract}
On 30 April-2 May, 2015, an inaugural Revenue Management Education Workshop on teaching Revenue Management (RM) was held at the University of Delaware. Made possible through generous support from Hyatt, the initiative was launched by Prof. Dr. Zvi Schwartz in order to facilitate a dialog among a selected group of hospitality RM educators and key industry players including: major international hotel chains, RM related technology and service providers and leading hospitality educators from worldwide universities. This article summarizes key themes emerged from the discussion and highlights the main challenges currently faced by RM educators.

Journal of Revenue and Pricing Management (2015) 14, 384-388. doi:10.1057/rpm.2015.26
\end{abstract}

Keywords: RevME; revenue management; education; teaching revenue management

On 30 April-2 May, more than 30 experts attended an inaugural Revenue Management
Education (RevME) workshop on teaching Revenue Management (RM) hosted by University of 
Delaware. The field of RM has already generated billions of dollars in profits and prevented bankruptcies worldwide. The demand for competent revenue managers - not only able to use data analytics to predict customer behavior, proactively formulate RM and pricing strategy but also possessing the necessary communication, decision making and leadership skills required to help a firm to maximize revenue is, however, growing rapidly.

The timely initiative was launched in partnership with Hyatt Hotels, Smith Travel Research and the Marriott Courtyard in Newark to provide a platform that facilitates a round-table discussion with a selected group of RM educators and key industry players on how to teach RM and equip future RM leaders.

After a very warm welcome from Mr Bruce Weber, the Dean of the School, the workshop started by exploring topics and trends in RM education. Several key topics and needs in RM education emerged through an interactive exercise. The outcome of this session shows that educators and industry practitioners share similar opinions on the current state of RM education and the difficulties they are facing. For example, most of the participants agreed that $\mathrm{RM}$ is a dynamic and multidisciplinary subject field that requires an integrated approach in teaching RM. However, the current educational materials are insufficient and there is a need for updated teaching resources and case studies. The other noticeable challenge is bridging theoretical rigor and practical relevance, which still poses a real challenge, especially in light of the wide range of (new) topics that a RM class needs to cover. In this context student skills were considered of immediate concern, whether dealing with tactical or more strategic aspects in RM education. Given recent advances in technology and Revenue Management Systems (RMS), as well as the expanding range of new specialist topics (for example, digital search marketing), it was also expected that educators' skills would soon be challenged to reflect the dynamic and holistic nature of the subject.

\section{THE INDUSTRY PERSPECTIVE}

The second session focused on understanding the industry expectations from RM leaders. During this session a panel of industry representatives shared their views on RM skills that they expect hospitality students to acquire and future RM practitioners should possess. The panel consisted of:

- Vice President of RM - Americas East from Marriott

- Director of RM from Hilton Worldwide

- Director of RMS Training \& Implementation at Starwood Hotels \& Resorts Worldwide

- Director of RM from Hyatt

- Regional Talent Acquisition Management from Hyatt.

All participants agreed that there is a great shortage of well-qualified revenue managers. Among the necessary qualities that are expected from a Revenue Manager, Mr Tim Heling (Revenue Director at Hyatt Regency Orlando) indicated that a potential candidate should have 'a hunger for continually questioning everything, and being self-motivated, competitive, analytically driven, with an ability to lead'. More importantly, he emphasized that 'a wellrounded individual who cares about customers as well as revenue would be the preferred candidate. Also, analytical skill is a must but the key is communication'. This view is echoed by Mr Calvin Anderson (Director of Revenue for Hilton Worldwide) who explained that in order to compete, the industry needs Revenue Managers who can improve market visibility and drive direct revenues using tools like predictive analytics, location-based marketing and social media advertising. He explained that Hilton is looking for candidates who possess both 'hard' and 'soft' skills. The former refers to one's ability to use Excel (including Pivot tables, VLOOKUP function and advanced graphing functionalities) and other analytics such as social media marketing analytics, predictive analytics, google analytics and so on. Knowledge and skills in Finance and Accounting were also 
identified as one of the hard skills that students should have. The latter refers to communication and leadership skills including diplomacy, mediation, and ability to be inspiring, motivational, creative and visionary.

Mr Calvin Anderson emphasized the fact that the lack of the so called RM 'talent' drives considerably higher salaries for Revenue Managers and it leads to exciting career opportunities. He recently interviewed 20 students from a leading hospitality program in the United States, but could not find even one suitable candidate for the internship position, while opportunities to make a good career are excellent. According to $\mathrm{Mr}$ Anderson a graduate with good RM knowledge and right attitude and motivation can realistically earn around 250000 USD within his or her first few years after graduation. The industry is 'hungry' for good candidates and these are golden opportunities both for educators and above all students in this dynamic and fascinating field.

Mr Jeff Borman (Vice President of RM, Marriott international) drew participants' attention to the need for improving students' ability to interpret data. He said that students should focus on 'the ability to merge different sources of data' and be able to handle dozens or more (!) sources of data. Just as important, he stressed that students should also be able to explain those findings to others in a clear way. It is key for the students to develop an 'ability to take data and translate them into something meaningful ... If you can get the students to figure that out sooner their career trajectory will skyrocket'. Another interesting insight was that in many leading hotel chains RM is proactively driving other functional areas including finance, marketing and operations. Mr John Anderson (Director of RM, Starwood Hotels) concluded the session by highlighting the need for an integrated approach to RM at a strategic level. He also suggested that RM education must include three key areas: leadership, communication and analytics.

\section{THE SERVICE PROVIDER'S PERSPECTIVE}

Technology and Business intelligence solutions increasingly play an important role in RM. During the workshop there were two sessions dedicated to exploring how providers of RM systems and business intelligence can be integrated in the classroom. Representatives from TravelClick, STR, Rainmaker and IDeaS shared their suggestions on how their technologies could be integrated in a curriculum, though the collaborative links between educators and system providers are in need of further exploration.

\section{THE EDUCATOR'S PERSPECTIVE}

During the workshop there were two sessions related to forecasting. The first session was on 'how to teach forecasting', where leading universities had the opportunity to share their approaches on how they teach this important topic. Pricing, inventory and cascade of other decisions in a hotel depend on the quality of the forecasts and ultimately drive the bottom-line performance. Therefore, it did not come as a surprise that many leading schools spend half of the semester on forecasting only!

At the end of the first day, a presentation on Forecasting Performance monitoring was given. There were many questions, and a very lively discussion arose on this topic. Both industry and education supported concerns about the way forecasting performance is measured at the moment. During the Q\&A part of the presentation, one of the RMS providers expressed a need to initiate a research collaboration and to explore the issue further. System providers (IDeaS and Rainmaker) were interested in exploring this topic and agreed on its importance.

\section{RM LEARNING RESOURCES}

Various learning resources were discussed during the workshop, including books and tools used in the classroom. The author of the book 
'Revenue Management: Maximizing Revenue in Hospitality Operations', Dr Gabor Forgacs shared his approach and demonstrated how he teaches Displacement analysis with the support of Excel. Dr Katerina Berezina demonstrated the M3Link, a software product that seamlessly reports PMS, Smith Travel Research, guest surveys, and financial data in one place, across all brands. Information is brought to one page with hundreds of viewing configurations of reports that are easy to read and compare.

\section{CASE STUDY - HYATT REGENCY ORLANDO}

A very insightful presentation was given by $\mathrm{Mr}$ Tim Heling, Revenue Director of the Hyatt Regency in Orlando. The property mainly works with conventions business, an aspect that often receives little attention in RM education. Interestingly, the decision horizon for his RM team currently is a 2016-2022 booking window: there are so many factors that might impact the future, and yet there also is a need to make some important decisions now. Again, this presentation confirmed that forecasting is a very important topic in real-life business environment.

Mr Heling also mentioned that RM in Hyatt Regency Orlando is leading many other departments and is taking proactive steps to drive not only revenue, but also profit, including a wide range of analysis relating to costs.

Mr Heling shared an example that if for example he or anyone on his team walks in the hotel and notices that a housekeeping department is not working efficiently, they can and will do something to improve it. It seems that $\mathrm{RM}$ is taking more and more a leading role in guiding decisions that do not only relate to revenue, but are connected to efficiency, cost optimization as well.

\section{CLOSING REMARKS AND PARTICIPANTS FEEDBACK}

The workshop concluded with an open session aimed to collect feedback of the participants on this first edition of the workshop. Both industry and educators acknowledged the usefulness and uniqueness of this event. The group was enthusiastic about making this event periodic and to involve more industry players and other educators. The organizers expressed their deep gratitude to the sponsors for their generous financial support and for making the event a priority and reality: Hyatt Hotels (Platinum), Smith Travel Research (Gold), and Marriott Courtyard Newark at the University of Delaware (Blue).

Taking into account that it was an inaugural event, few points were collected on how a next edition could evolve to align with the needs of the educators and the industry. For example, the program touched upon a wide range of topics, but the selection of the topics was somewhat arbitrary. The organizers agreed to modify their approach for the selection of topics and the program design to better accommodate the needs of the discipline and the industry for the next edition of the RevME workshop. Second, the official meeting agenda was focused solely on teaching. Not discussing research means that advanced degree contexts (Masters and $\mathrm{PhD}$ ) were excluded from considerations, together with the research activity of faculty that in majority of cases constitutes an important (if not dominant) part of academic life. The organizers are planning to address this issue in the future by including research sessions and working with the industry on research collaboration. Another future opportunity would be to have a session on RM simulation software where participants could share experiences on the pros and cons of RM simulations that are currently available on the market.

\section{CONCLUSION}

What set this event apart from any other academic or business events on RM, was the fact that educators and industry players were gathered in the same space for 2 whole days discussing and evaluating what is taught at the moment and what are current and future needs. This event offered an excellent opportunity for 
the participants to discuss cutting edge RM practices, share their ideas, experience and information on how to teach RM as well as cultivating a closer working relationship between RM educators, hospitality employers and RM industry vendors who have vested interests in the level of RM skills students acquire.

The workshop was the first of its kind. It offered a platform for RM educators and industry practitioners to share and to exchange their knowledge and experience. It has paved the way for narrowing down the gap between what the educators teach at University and what industry expect from hospitality management graduates especially those who wish to pursue a career in RM. The sessions were insightful and thought-provoking. The outcomes of this workshop have already initiated further discussions among the participants, which will shape the future RM curriculum. 